\title{
POLICY Understanding the enablers and barriers to implementing smoke-free NHS sites across acute care trusts in Greater Manchester: results of a hospital staff survey
}

\author{
Authors: Hannah Clegg, ${ }^{\mathrm{A}}$ Freya Howle, ${ }^{\mathrm{B}}$ Kathryn Groom, ${ }^{\mathrm{C}}$ Ryan Moore, ${ }^{\mathrm{D}}$ Lynn Hryhorskyj, ${ }^{\mathrm{E}}$ Seamus Grundy, ${ }^{\mathrm{F}}$ \\ Alex Tempowski, ${ }^{\mathrm{G}}$ Beth Turnpenny, ${ }^{\mathrm{H}}$ Hou Law, ${ }^{\mathrm{I}}$ Ram Sundar, ${ }^{\mathrm{J}}$ Al-Tahoor Butt, ${ }^{\mathrm{K}}$ Muntasir Abdelaziz, ${ }^{\mathrm{L}}$ \\ Sanjay Agrawal, ${ }^{\mathrm{M}}$ Jane Coyne, $^{\mathrm{N}}$ Andrea Crossfield ${ }^{\mathrm{O}}$ and Matthew Evison ${ }^{\mathrm{P}}$
}

\section{Introduction}

The current study aims to identify enablers and barriers to implementing smoke-free NHS hospital grounds through a hospital staff survey.

\section{Methods}

Staff members from eight acute care NHS trusts in Greater Manchester were invited to complete a 15-minute web-based questionnaire.

Results

Five-hundred and eighty-eight participants completed the questionnaire. Nineteen per cent $(114 / 588)$ of respondents were current smokers and $10 \%(61 / 588)$ were currently vaping. Sixty per cent $(68 / 114)$ smoked at work and $66 \%(40 / 61)$ vaped at work. Sixty-seven per cent (314/468) supported dedicated on-site tobacco addiction treatment services for hospital staff with specific support for drop-in clinics and free

Authors: ${ }^{\mathrm{A} C U R E}$ research assistant, Greater Manchester Cancer, Greater Manchester, UK; ${ }^{\mathrm{B}}$ CURE programme manager, Greater Manchester Cancer, Greater Manchester, UK; ' ${ }^{C}$ URE assistant programme manager, Greater Manchester Cancer, Greater Manchester, UK; ${ }^{\mathrm{D}}$ CURE assistant programme manager, Greater Manchester Cancer, Greater Manchester, UK; E ${ }^{\text {general practitioner }}$ trainee, Bowland Medical Practice, Manchester, UK; ${ }^{F}$ consultant in respiratory medicine, Northern Care Alliance, Greater Manchester, UK; ${ }^{G}$ consultant in respiratory medicine, Stepping Hill Hospital, Greater Manchester, UK; ${ }^{H}$ consultant in respiratory medicine, Fairfield Hospital, Greater Manchester, UK; ${ }^{\mathrm{I}}$ consultant in respiratory medicine, Royal Oldham Hospital, Greater Manchester, UK; ' consultant in respiratory medicine, Royal Albert Edward Infirmary, Greater Manchester, UK; ${ }^{{ }}$specialist trainee in respiratory medicine, Tameside General

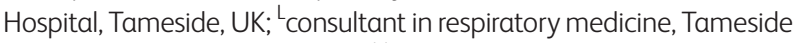
General Hospital, Tameside, UK; ${ }^{M}$ consultant in respiratory medicine, Glenfield Hospital, Leicester, UK; N programme manager, Greater Manchester Health and Social Care Partnership, Greater Manchester, UK; ${ }^{{ }^{O}}$ strategic lead, Greater Manchester Health and Social Care Partnership, Greater Manchester, UK; ${ }^{P}$ consultant in respiratory medicine, Wythenshawe Hospital, Greater Manchester, UK pharmacotherapy for staff. Sixty-one per cent (290/477) and $67 \%$ (318/477) strongly agreed / agreed that patients/visitors and staff, respectively, should not smoke on hospital grounds. Seventeen per cent $(83 / 484)$ had received training in very brief advice. Thirty-five per cent (190/547) felt vaping was less harmful than smoking, $19 \%$ (92/472) felt exhaled vapour was likely to be safe to bystanders, $36 \%(172 / 475)$ would support vaping-friendly hospital grounds and $31 \%(37 / 120)$ felt confident in discussing vaping.

\section{Discussion}

Enablers to a smoke-free NHS site include dedicated tobacco addiction services for staff and empowering staff through appropriate training to support smokers on the hospital grounds. Barriers include the lack of awareness and support for the harm reduction benefits of vaping.

KEYWORDS: tobacco dependency, smoke free

DOI: 10.7861/fhj.2020-0243

\section{Introduction}

Smoking is the single largest cause of preventable death and there are approximately 7 million adults that currently smoke in the UK. ${ }^{1,2}$ As part of the UK government's prevention green paper, a goal was set for England to be smoke-free by $2030 .^{3}$ In support of this motion, hospitals across the UK are making a national effort to adopt smoke-free policies across their sites. In 2018, the Royal College of Physicians (RCP) stated that smoke-free hospital policies are required to protect people from breathing in second-hand smoke, given there is no safe level of exposure to tobacco smoke, and to support patients, staff and visitors that smoke to be smoke free while on the hospital grounds. ${ }^{1}$ Despite these recommendations, compliance with smoke-free hospital grounds has been poor. A British Thoracic Society (BTS) audit of 140 UK acute hospital trusts found that the majority of trusts described their compliance with a smoke-free status as 'rarely' or 'not at all'. ${ }^{4}$ Furthermore, electronic cigarettes ('vaping') have been demonstrated to be an effective tool to achieve abstinence from tobacco and Public Health England (PHE) recommends that 
hospital trusts develop vaping-friendly approaches to support smoke free sites, exclude vaping from smoke-free policies, consider vaping distinct from smoking and permit vaping on hospital sites. ${ }^{5-7}$ The current study aims to understand smoking and vaping behaviour across acute care NHS staff, in addition to understanding the existing knowledge, opinion and attitudes of NHS staff to smoking, vaping and smoke-free hospital sites. The results may help us understand the barriers and enablers to delivering smoke-free NHS sites that may, in turn, support trusts in developing effective policies and strategies for becoming smoke-free sites.

\section{Methods}

A self-reported survey of staff attitudes towards smoking, vaping and smoke-free NHS hospital grounds was conducted using a 15-minute web-based questionnaire. The survey was distributed via repeated internal email communications containing a link to the online survey. The survey was also advertised via trust screensavers with QR codes and distributed flyers in staff rooms with QR codes to allow access to the survey via a smartphone or tablet. Hospital staff members from eight participating acute care trusts in Greater Manchester were invited to complete the survey. All hospital staff members (including medical, nursing, administrative, managerial, healthcare assistants, allied healthcare professionals, porters and support staff) were eligible to complete the survey, which contained five sections (Table 1).

Section 1 examined smoking and vaping behaviour among hospital staff. Active smokers were asked about the level of tobacco dependency using the Heaviness of Smoking Index (HSI) and whether they smoked at work on the hospital site. ${ }^{8}$ Active vapers were asked if they vaped on hospital grounds while at work. Section 2 investigated staff knowledge and opinions of key concepts in tobacco addiction. Firstly, participants were asked to reflect on four statements that provided education on key concepts in tobacco addiction (full statements in Table 2):

$>$ the severity of harm caused by smoking tobacco

$>$ the lack of harm caused by nicotine

$>$ the pathology of the disease of tobacco addiction

$>$ the high efficacy of tobacco addiction pharmacotherapy.

Participants were asked to select one of three answers:

$>$ already aware of the information

$>$ not aware and the information has changed how they think about smoking

Table 1. Overview of the Greater Manchester hospital staff survey on smoking, vaping and smoke-free hospital grounds

\begin{tabular}{|c|c|c|}
\hline Section & Theme & Questions \\
\hline \multirow[t]{5}{*}{ Section 1} & \multirow{5}{*}{$\begin{array}{l}\text { Smoking and vaping behaviour among } \\
\text { hospital staff }\end{array}$} & Smoking status \\
\hline & & Level of tobacco addiction (Heaviness of Smoking Index (HSI)) \\
\hline & & Smoking activity on hospital grounds \\
\hline & & Vaping status \\
\hline & & Vaping activity on hospital grounds \\
\hline \multirow[t]{6}{*}{ Section 2} & \multirow{6}{*}{$\begin{array}{l}\text { Knowledge and opinion in key } \\
\text { concepts in tobacco addiction }\end{array}$} & Knowledge of the severity from smoking tobacco \\
\hline & & Knowledge of the lack of harm from nicotine \\
\hline & & Knowledge of the pathology of tobacco addiction \\
\hline & & $\begin{array}{l}\text { Knowledge of the high efficacy of tobacco addiction } \\
\text { pharmacotherapy }\end{array}$ \\
\hline & & Opinion of harm of vaping in comparison with smoking (Likert scale) \\
\hline & & Opinion of harm from exhaled vapour to bystanders \\
\hline \multirow[t]{3}{*}{ Section 3} & \multirow{3}{*}{$\begin{array}{l}\text { Level of training and confidence in } \\
\text { delivering tobacco addiction } \\
\text { interventions }\end{array}$} & Completion of training in VBA \\
\hline & & Level of confidence in delivering VBA (Likert scale) \\
\hline & & Level of confidence in discussing vaping (Likert scale) \\
\hline \multirow[t]{5}{*}{ Section 4} & \multirow[t]{5}{*}{$\begin{array}{l}\text { Successful delivery of a smoke-free } \\
\text { hospital site }\end{array}$} & $\begin{array}{l}\text { Level of agreement that patients and visitors should not smoke on the } \\
\text { hospital grounds (Likert scale) }\end{array}$ \\
\hline & & $\begin{array}{l}\text { Level of agreement that staff should not smoke on the hospital } \\
\text { grounds (Likert scale) }\end{array}$ \\
\hline & & $\begin{array}{l}\text { Level of agreement that hospital grounds should be vaping friendly } \\
\text { (Likert scale) }\end{array}$ \\
\hline & & $\begin{array}{l}\text { Level of agreement that comprehensive tobacco addiction } \\
\text { interventions should be available on site for staff that smoke (Likert } \\
\text { scale) }\end{array}$ \\
\hline & & Support for individual smoke-free site interventions \\
\hline Section 5 & Free-text responses & Free-text comments regarding delivering smoke-free hospital grounds \\
\hline
\end{tabular}


Table 2. Statements presented to participants to assess knowledge and opinion on tobacco addiction

Statement

1) Smoking cigarettes is the single biggest cause of preventable death and illnesses and is a major cause of the three most common causes of death (cancer, heart attack and lung disease). One in two smokers die young because of their smoking. Smoking causes 16 different kinds of cancer.

2) Although nicotine is the highly addictive chemical in cigarettes it is not the reason smoking causes diseases and death. Nicotine itself is pretty harmless and is actually a very similar chemical to caffeine (just works in a different part of the brain). It is the 5,000 other chemicals in cigarettes that cause all the damage. There are much safer ways of getting nicotine without cigarettes.

3) Nicotine is the highly addictive chemical in cigarettes. It works in the brain by releasing a hormone (dopamine) that is a calming and relaxing hormone. However, over time the brain becomes dependent on nicotine and, without it, suffers intense withdrawal symptoms. This addiction is a physical disease, not a lifestyle choice. Every person deserves to have access to the best treatments for any disease they suffer with. This includes the disease of smoking.

4) There are some very effective medications to help a smoker to stop. Nicotine replacement therapy (NRT) is very effective but must be used at a big enough dose to match the nicotine provided in a cigarette. This can sometimes mean using NRT as often as every hour on the hour. There are highly effective tablet treatments that block the effect of nicotine in the brain and break the cycle of addiction. All healthcare professionals have a responsibility to understand the disease of smoking and how to provide medications for it.

> not aware and the information has not changed how they think about smoking.

Secondly, participants were asked to provide an opinion on two areas regarding vaping, using a five-point Likert scale; their level of agreement with the statement 'e-cigarettes are less harmful than cigarettes' ranging from 'strongly agree' to 'strongly disagree' and their understanding on the risk of the vapour exhaled by users of e-cigarettes to bystanders ranging from 'very safe' to 'very harmful'.

Section 3 examined the level of training and confidence in delivering tobacco addiction interventions among hospital staff. Participants were asked if they had received formal training on delivering very brief advice (VBA) and then to provide their level of confidence in delivering VBA and in discussing and advising about vaping with smokers on the hospital site both using a five-point Likert scale ranging from 'very confident' to 'very unconfident'.

Section 4 examined the views of staff members on successfully delivering smoke-free hospital grounds by asking participants to provide their level of agreement, via a five-point Likert scale to four statements:
$>$ patients and visitors should not be allowed to smoke on the hospital grounds

> staff should not be allowed to smoke on hospital grounds

> the hospital should allow the use of vaping on the hospital grounds to help prevent smoking tobacco

> comprehensive tobacco addiction interventions should be available on-site for staff that smoke.

Next, participants were provided with a list of specific interventions a hospital could implement to help deliver a smokefree site and were asked to select all interventions they felt would be successful and which they would support.

Section 5 allowed participants to provide any free-text comments about smoke-free hospital grounds. A thematic analysis was conducted on the qualitative data, to extract key themes within the responses. The survey was live from October 2019 to May 2020 and data analysis was conducted in June 2020. Not all participants answered all questions and so the denominator for each individual question is provided within the results section. Every answer provided by all participants has been included in the analysis.

\section{Results}

A total of 588 participants completed the online questionnaire. Respondents hold a wide range of roles within their respective trusts: 165 (28\%) administrative staff, 153 (26\%) nursing staff, 56 $(10 \%)$ managerial staff, 35 (6\%) healthcare assistants, 33 (6\%) doctors and $36(6 \%)$ allied health professionals. The remaining $18 \%$ of respondents hold miscellaneous positions within their trust or did not specify their job role (research $n=14$; education team $n=13$; domestics $n=4$; executive team $n=3$; food and catering $n=1$; other $n=30$; and respondents that did not specify their job role $n=45$ ).

\section{Section 1: Smoking and vaping behaviour among hospital staff}

Nineteen per cent $(114 / 588)$ of participants self-reported as being an active smoker. Of those staff members who smoked, $60 \%(68 / 114)$ reported smoking while at work. In relation to the HSI, 26\% reported taking less than 5 minutes to smoke their first cigarette after waking up, with $39 \%$ reporting smoking within less than 30 minutes and $35 \%$ taking more than 30 minutes. Ten per cent $(n=61)$ of participants self-reported as current vapers. Of these individuals, $66 \%(40 / 61)$ reported vaping at work.

\section{Section 2: Knowledge and opinions in key concepts in tobacco addiction}

Across all four statements on key concepts in tobacco addiction, most respondents reported already being aware of the knowledge provided (Fig 1). Ninety-eight per cent (500/512) of respondents were already aware of the severity of harm from smoking tobacco (eg one in two smokers die prematurely and smoking causes 16 different kinds of cancer). Seventy-eight per cent (404/515) of respondents were aware of the lack of harm from nicotine and that the harms of smoking are derived from the additional chemicals produced from the combustion of tobacco. The remaining $22 \%(111 / 515)$ were not aware of this information and in $9 \%$ (47/515), this changed their views and understanding on smoking. Seventy-eight per cent (398/512) 


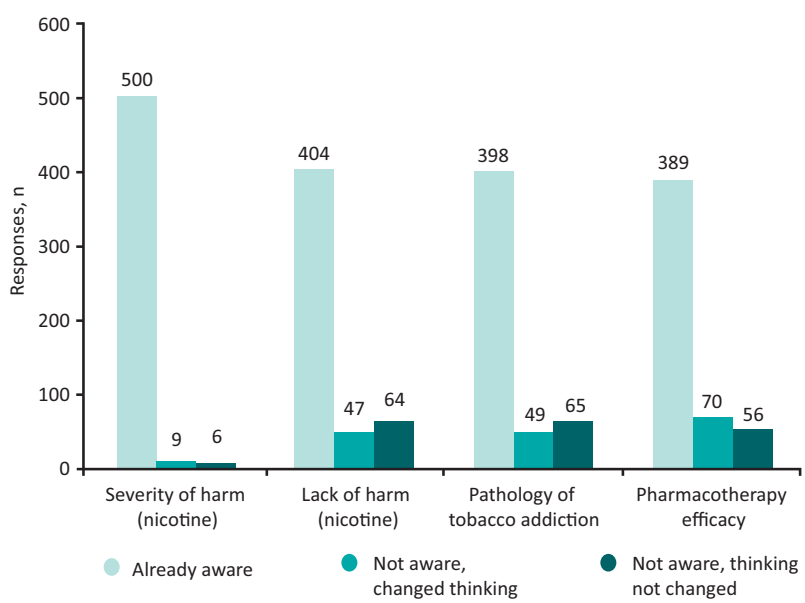

Fig 1. Knowledge of hospital staff in key concepts of tobacco addiction.

were aware of the pathology of tobacco addiction through development of dependency to nicotine in the brain due to dopamine release, and that this represents a physical disease rather than a lifestyle choice. Ten per cent (49/512) stated this new information had changed their viewpoint on smoking while $13 \%(65 / 512)$ stated it had not. Seventy-six per cent (389/515) of staff members were aware of the high level of effectiveness of tobacco addiction pharmacotherapy and the responsibility of healthcare professionals to provide access to these interventions. Fourteen per cent (70/515) stated that this information changed the way they think about smoking and $11 \%$ (56/515) stated it had not.

Regarding respondents' opinions of the safety versus harms of vaping, 35\% (190/547) of respondents strongly agreed or agreed with the statement 'e-cigarettes are less harmful than cigarettes' (Fig 2). Opinions on the safety versus harm to bystanders from the vapour exhaled during vaping were mixed: $3 \%$ (15/472) answered 'very safe', 16\% (77/472) answered 'probably safe', 44\% (206/472) were 'unsure', 31\% (148/206) answered 'probably harmful' and 6\% (26/472) answered 'very harmful'.
Section 3: Level of training and confidence in delivering tobacco addiction interventions

Seventeen per cent $(83 / 484)$ of participants stated that they had been trained in giving very brief advice to people that smoke. Levels of confidence in providing brief advice and discussing or advising smokers about vaping were low with $11 \%$ (51/484) and $7 \%(8 / 120)$ of respondents feeling 'very confident' in these two areas, respectively, and 20\% (95/484) and 24\% (29/120) feeling 'confident', respectively. All other responses with 'neither agree nor disagree', 'unconfident' or 'very unconfident' (Fig 3).

\section{Section 4: Successful delivery of a smoke-free hospital site}

From 477 participant responses, there was strong support for a smoke-free site: 61\% (290/477) and 67\% (318/477) 'strongly agreed' or 'agreed' that patients, visitors and staff should not smoke on the hospital grounds, respectively (Fig 2). However, opinion regarding patients, visitors and staff having permission to use an e-cigarette on hospital grounds, in lieu of smoking, was mixed. From 475 responses, 10\% (49/475) strongly agreed and $26 \%$ (123/475) agreed with vaping-friendly grounds compared with $21 \%(99 / 475)$ of respondents that strongly disagreed and $20 \%$ (97/475) that disagreed. From 468 respondents, most supported the provision of on-site tobacco addiction interventions for staff that smoke with 34\% $(n=157)$ reporting that they 'strongly agreed' and a further $34 \%(n=157)$ reporting that they 'agreed'.

There was strong support for a number of interventions to support a smoke-free site including 'drop-in' stop smoking clinics at the hospital available for any visitor or staff member that smokes, free medications for staff that smoke to help not to smoke on the hospital grounds, increased smoke-free signage across the hospital grounds and increased security patrols to support smoke-free grounds. The less popular interventions were having e-cigarettes available at the hospital, vaping friendly grounds and recorded messages at hospital entrances (Fig 4).

\section{Section 5: Qualitative comments}

Thirty per cent (178/588) of respondents provided free-text comments on smoke-free hospital grounds. A thematic analysis

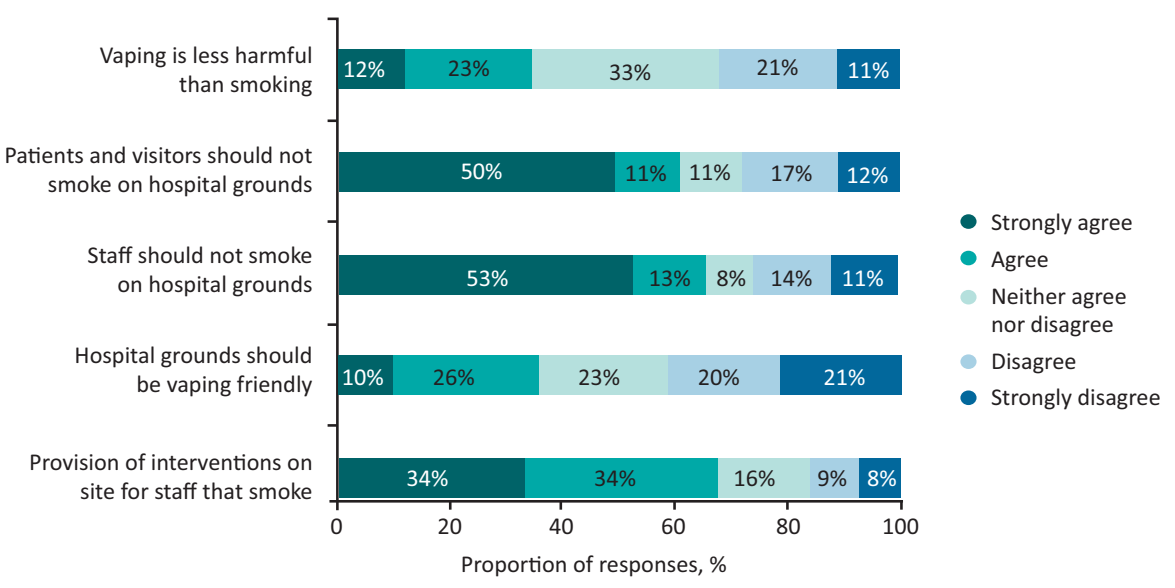

Fig 2. Summary of 'level of agreement' Likert scale questions and answers. 


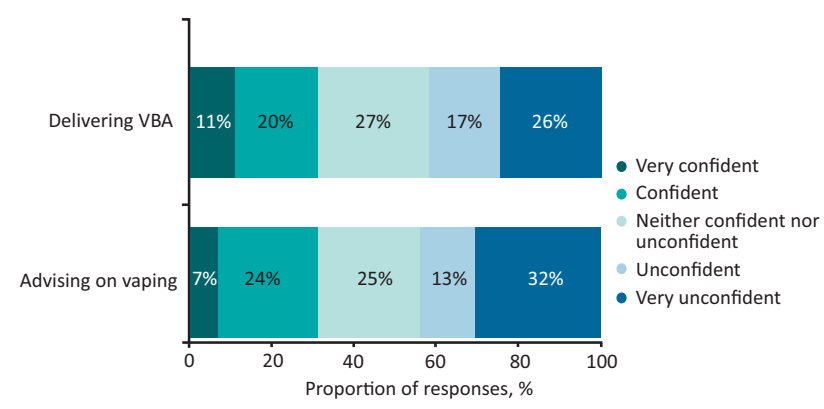

Fig 3. Summary of 'level of confidence' Likert scale questions and answers. VBA = very brief advice.

of these free-text responses highlighted strongly held but opposing opinions of support for designated smoking areas $(n=75)$ and support for fully enforced smoke-free policies $(n=46$; Table 3$)$. The support for designated smoking areas centred on the following themes and viewpoints: it is an impossible task to truly implement smoke-free sites and that dedicated smoking shelters keep those smoking away from non-smokers; a person's right to smoke should be respected; allowing a patient to smoke can play a helpful role in anxiety or anger management; and that challenging a person smoking on the hospital grounds risks aggression or confrontation. The support for smoke-free sites centred on the following themes and viewpoints: a personal displeasure of being exposed to second-hand smoke in the workplace and the importance of hospitals setting an example of healthy lifestyles. The number of free-text comments pertaining directly to the use of e-cigarettes within smoking cessation treatment and smokefree grounds policy was low $(n=21)$ but were mostly negative $(n=17)$. Many comments considered smoking and vaping to be similar entities with similar harm profiles and, therefore, requiring similar action or policy (Table 3 ).

\section{Discussion}

Approximately one in five of respondents in this large survey of acute care NHS staff (total $n=588$ ) were active smokers and two-thirds of these active smokers had high levels of dependency and smoked at work. One in 10 respondents were active vapers and two-thirds vape at work. It is highly likely, therefore, that active smokers are over-represented in this study as the national smoking prevalence is $14.1 \%$ and the estimated smoking prevalence across healthcare workers by the RCP is $6.2 \%{ }^{1,9}$ Increased risk of smoking within healthcare professionals has been previously noted, with high levels of workplace stress and long working hours being attributed as potential motivators. ${ }^{10,11}$ Furthermore, many healthcare professionals note difficulty accessing smoking cessation services as a factor in not making successful attempts to quit. ${ }^{12}$ Within this survey, where active smokers are likely to be over-represented, there is strong support for the provision of on-site tobacco addiction treatment services for staff ( $68 \%$ strongly agree / agree) and the two most supported specific interventions for successful delivery of a smoke-free site were drop-in clinics for staff (and visitors) with the tobacco addiction treatment service and free prescriptions for tobacco addiction pharmacotherapy for staff. This is, therefore, a call to arms for acute care trusts to recognise the unmet need of staff that smoke and the opportunity to improve productivity, reduce sick days and deliver smoke-free environments through the provision of easily accessible tobacco addiction treatment services for staff on site. For those staff members that vape, these results support national recommendations that smoke-free sites are vaping friendly to adequately support this group in abstaining from smoking tobacco at the workplace and beyond.

While the knowledge of the harms of smoking seem to be very well understood, the awareness of the lack of harm from nicotine, the pathology of the disease of tobacco addiction and the high levels of effectiveness of stop smoking pharmacotherapy is lower (Fig 1). This represents an opportunity to increase the awareness and change the viewpoint of hospital staff towards smoking, which may, in turn, lead to staff feeling more empowered to discuss these key concepts in tobacco addiction and support smokers better. Furthermore, there was strong support for smokefree NHS sites (approximately two-thirds strongly agree / agree with smoke-free hospital grounds including patients, visitors and staff) and recognition that both individual healthcare professionals and hospital trusts have a responsibility to offer help to smokers. However, there were low rates of training in VBA across hospital staff (less than one in five had received training in
Fig 4. Level of support for specific interventions for successful delivery of smoke-free hospital sites.

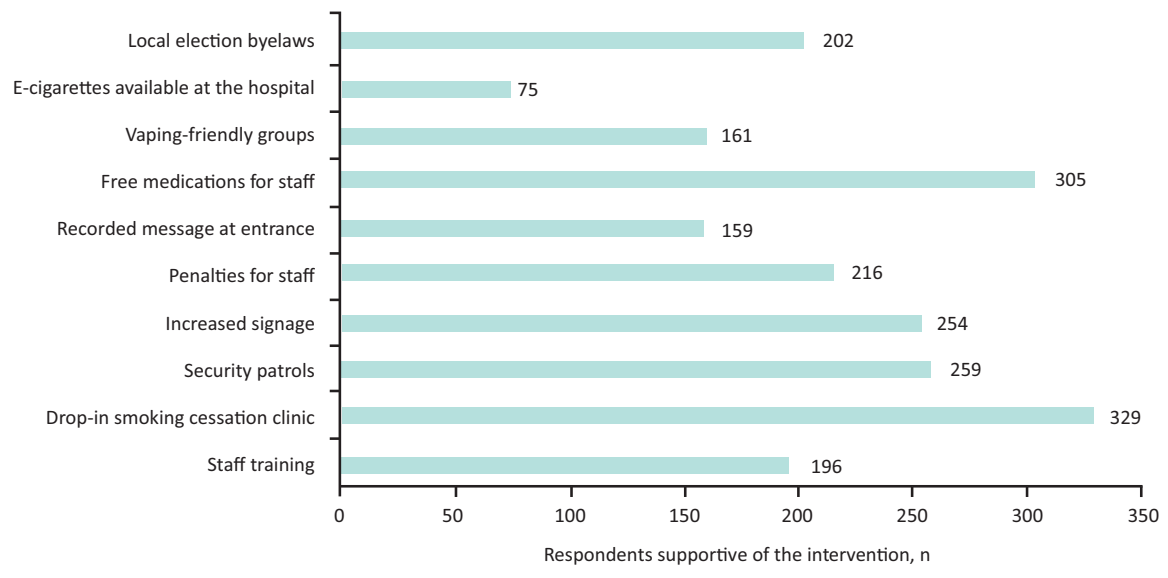




\section{Table 3. Examples of free-text comments categorised into common themes}

\begin{tabular}{|c|c|}
\hline Theme & Examples of comments \\
\hline \multirow[t]{5}{*}{$\begin{array}{l}\text { Support for smoking } \\
\text { shelters or allowing } \\
\text { smoking on the hospital } \\
\text { grounds }\end{array}$} & $\begin{array}{l}\text { I wouldn't like to see the hospital banning smoking on the premises as it discriminates against workers } \\
\text { who smoke ... and for patients who smoke, a hospital stay would become very difficult indeed. Provision } \\
\text { should be made for smokers ... as with any other group people, to make sure their needs are allocated for } \\
\text { and respected. }\end{array}$ \\
\hline & Smoking is still legal and, as such, the hospital should continue to provide designated smoking areas. \\
\hline & $\begin{array}{l}\text { Patients should not be stopped from smoking in hospital, it is completely impractical. The risk of } \\
\text { aggression to staff from patients who are denied the right to smoke would put staff at risk. }\end{array}$ \\
\hline & $\begin{array}{l}\text { I feel that as a nurse caring for patients on the wards, to stop them going for a cigarette would leave staff } \\
\text { very vulnerable to physical and verbal abuse. }\end{array}$ \\
\hline & $\begin{array}{l}\text { In my experience, sometimes when a patient is not allowed or unable to smoke, it can significantly affect } \\
\text { their mood, stress levels, motivation and behaviour negatively - in my opinion smoking affects you more } \\
\text { psychologically than physically. }\end{array}$ \\
\hline \multirow[t]{4}{*}{$\begin{array}{l}\text { Support for smoke-free } \\
\text { hospital grounds }\end{array}$} & $\begin{array}{l}\text { I feel very strongly that any hospital or healthcare site should always promote 'best practice' and healthy } \\
\text { lifestyle with everything they do to set the best example. }\end{array}$ \\
\hline & $\begin{array}{l}\text { As a non-smoker, I really hate walking at any of the entrances through smoke or vapour clouds. I don't } \\
\text { object necessarily to people smoking, as it is their choice, but I should not have to be exposed to it - that } \\
\text { is my choice. }\end{array}$ \\
\hline & $\begin{array}{l}\text { We are supposed to be promoting healthy lifestyles and improving national health statistics. By turning } \\
\text { a blind eye, we are failing the population. Unless fines and restrictions are in place and implemented } \\
\text { regularly then nothing will change. }\end{array}$ \\
\hline & $\begin{array}{l}\text { Stop messing about and simply ban smoking on hospital grounds. This has gone on long enough. It's } \\
\text { disgraceful and raises ethical questions that we continue to allow smoking on healthcare premises. }\end{array}$ \\
\hline \multirow{3}{*}{$\begin{array}{l}\text { Concerns raised over vaping } \\
\text { on hospital grounds }\end{array}$} & I find vaping equally distressing - and several deaths from vaping have been reported in the USA. \\
\hline & $\begin{array}{l}\text { The health service should NOT be providing advice to people to USE e-cigarettes. Emerging evidence is } \\
\text { starting to suggest that they are just as bad, if not worse than normal cigarettes, and until that evidence } \\
\text { is clear, we shouldn't be promoting this as an option. }\end{array}$ \\
\hline & $\begin{array}{l}\text { We live in a culture of litigation - and promoting vapes and e-cigs as an alternative is a class-action suit } \\
\text { waiting to happen! }\end{array}$ \\
\hline \multirow[t]{2}{*}{$\begin{array}{l}\text { Support for vaping on } \\
\text { hospital grounds }\end{array}$} & $\begin{array}{l}\text { Unfortunately, both smokers and vapers are currently treated the same way. Smokers should be } \\
\text { encouraged to at least try (for maybe one month+) to solely vape as a safer alternative. }\end{array}$ \\
\hline & Trust policies and signage should be changed to help smokers think about switching. \\
\hline
\end{tabular}

VBA) and low levels of confidence in delivering VBA (approximately one-third of respondents felt very confident or confident in delivering VBA). This, worryingly, creates a significant mismatch between the enthusiasm of hospital staff to be part of smokefree environments and to be provided with the tools required to support smokers and the actual provision of the required training. This is in keeping with the findings from the BTS National Smoking Cessation Audit where low levels of training provision were also reported. ${ }^{4}$

In respondents to this survey, there is a lack of awareness of the risk reduction that vaping provides in comparison with smoking tobacco, a lack of confidence in discussing vaping, a lack of knowledge in the relative safety of exhaled vapour to bystanders and a lack of support for vaping friendly hospital grounds, all findings consistent with previous research. ${ }^{13}$ These findings represent a significant barrier to implementing a smoke-free NHS site and are in direct opposition to national policy and guidance. Vaping has been confirmed to be significantly more effective as a smoking cessation intervention in comparison with nicotine replacement therapy in both a large randomised controlled trial and in a large Cochrane review. ${ }^{5,6}$ Unlike cigarettes, there is no side-stream vapour emitted by an e-cigarette into the atmosphere, just the exhaled aerosol. Public Health England's 2018 evidence review found that, to date, there have been no identified health risks of passive vaping to the health of bystanders. ${ }^{14}$ Given their effectiveness as a smoking cessation intervention, it is important that smokers have access to this intervention on the hospital grounds to prevent a relapse to or use of tobacco. It is likely, therefore, that vaping will be a critical component of successful delivery of a smoke-free hospital site. Providing a detailed educational package and communications strategy, alongside smoke-free site implementation, on the potential benefits of vaping within smoking cessation and its role in harm reduction could aid in addressing the gaps in knowledge regarding vaping. Such an educational and communication package could also address some of the barriers and perceptions raised in the thematic analysis of the free-text comments. This might include the reasoning behind smoke-free hospital environments not 
just as protection to others from second-hand smoke but as the significant benefit to the individual, the release of hospital resources through reduced length of stay and re-admissions, and the support of those trying to be smoke free by reducing the visual cues and triggers to smoke. ${ }^{15,16}$ It may also include the management of nicotine withdrawal in patients to prevent staff supporting smoking breaks for patients and changing the process of approaching smokers on the hospital grounds to an offer of support not a challenge or confrontation to stop.

\section{Strengths and weaknesses of the study}

A strength of the current study is that it encapsulates a wide scope of different staff roles within the hospital environment and a very large cohort of nearly 600 respondents. Previous surveys of staff attitudes towards smoking focus heavily on clinician opinion rather than those of nursing staff and healthcare assistants, who will usually make the first engagement with patients that smoke. Furthermore, administrative, managerial and other non-healthcare professionals may not have received the same level of medical education regarding smoking due to the differing nature of their job roles. It is, therefore, important to consider the opinion of all hospital staff, not just members working in a healthcare role. However, the weakness of this study is the number of staff completing this survey represents a very small fraction of the entire NHS workforce in employment across this large healthcare conurbation (we estimate less than $3 \%$ of the workforce eligible to complete the survey did so). It would be wrong to conclude, therefore, that the results of this survey truly represent the views of the entire NHS workforce. Inherently, there is selection bias in these results as those completing this survey are likely to represent those most motivated to provide their viewpoint. This could represent those with the most polarised views either in support or against smoke-free NHS sites. The use of email communications and QR codes for survey access and invitation may also create a selection bias through digital exclusion, preventing those staff members without digital access to complete the survey.

\section{Conclusion}

The results of this survey suggest the enablers to a smoke-free NHS site include addressing the unmet needs of hospital staff that smoke and vape on the hospital grounds, amplifying the strong support from NHS staff for smoke-free sites through comprehensive training packages on supporting smokers at the hospital site and implementing a vaping-friendly hospital ground policy but only alongside a dedicated educational package focusing on the risk reduction of vaping. Barriers to a smoke-free site include the current negative views on vaping as a facilitator for smoke-free sites and viewpoints on the need to allow patients to smoke as part of behavioural management, the right of individuals to choose to smoke on hospital grounds and the fear of confrontation from challenging smokers on hospital grounds.

\section{References}

1 Royal College of Physicians. Hiding in plain sight: Treating tobacco dependency in the NHS. RCP, 2018.

2 Hopkinson NS. The path to a smoke-free England by 2030. BMJ 2020;368:m518.

3 Briggs A, Elwell-Sutton T. The prevention green paper: blink and you'll miss it. BMJ 2019;366:14913.

4 Mangera Z, Devani N. National Smoking Cessation Audit Report 2019. British Thoracic Society Reports 2020;11:1-14.

5 Hajek P, Phillips-Waller A, Przulj D et al. A randomized trial of e-cigarettes versus nicotine-replacement therapy. N Engl J Med 2019;380:629-37.

6 Hartmann-Boyce J, McRobbie H, Butler AR et al. Can electronic cigarettes help people stop smoking, and do they have any unwanted effects when used for this purpose? Cochrane Database of Systematic Reviews 2021:CD010216.

7 Public Health England. Use of e-cigarettes in public places and workplaces: Advice to inform evidenced-based policy making. Public Health England, 2016.

8 Heatherton TF, Kozlowski LT, Frecker RC, Rickert W, Robinson ]. Measuring the heaviness of smoking: using self-reported time to the first cigarette of the day and number of cigarettes smoked per day. Br J Addict 1989;84:791-9.

9 Office for National Statistics. Adult smoking habits in the UK: 2019. ONS, 2020.

10 Abou-EIWafa HS, Zoromba MA, El-Gilany AH. Cigarette smoking at workplace among resident physicians and nurses in Mansoura University Hospital. Arch Environ Occup Health 2021;76:37-44.

11 LeBlanc AG, Prince SA, Reid RD et al. Smoking behaviour among nurses in Ontario: cross-sectional results from the Champlain Nurses' Study. Can J Public Health 2020;111:134-42.

12 Ratier-Cruz A, Smith JG, Firn M, Rinaldi M. Staff attitudes to completely smoke-free policies and smoking cessation practices in a mental health setting. J Public Health (Oxf) 2020;42:403-11.

13 Conlon K, Pattinson L, Hutton D. Attitudes of oncology healthcare practitioners towards smoking cessation: A systematic review of the facilitators, barriers and recommendations for delivery of advice and support to cancer patients. Radiography (Lond) 2017;23:256-63.

14 McNeill A BL, Calder R, Bauld L, Robson D. E-cigarettes and heated tobacco products: evidence review. Public Health England, 2018.

15 Mullen KA, Manuel DG, Hawken S] et al. Effectiveness of a hospitalinitiated smoking cessation programme: 2 -year health and healthcare outcomes. Tob Control 2017;26:293-9.

16 Evison M, Agrawal S, Conroy M et al. Building the case for comprehensive hospital-based tobacco addiction services: Applying the Ottawa Model to the City of Manchester. Lung Cancer 2018;121:99-100.

Address for correspondence: Dr Matthew Evison, Wythenshawe Hospital, Manchester University NHS Foundation Trust, Southmoor Road, Wythenshawe, Manchester M23 9LT, UK.

Email:m.evison@nhs.net

Twitter: @MatthewEvison1 